\title{
The Pain Dynamics of Small Fiber Neuropathy
}

Citation for published version (APA):

Brouwer, B. A., van Kuijk, S. M. J., Bouwhuis, A., Faber, C. G., van Kleef, M., Merkies, I. S. J., \& Hoeijmakers, J. G. J. (2019). The Pain Dynamics of Small Fiber Neuropathy. The Journal of Pain, 20(6), 655-663. https://doi.org/10.1016/j.jpain.2018.11.009

Document status and date:

Published: 01/06/2019

DOI:

10.1016/j.jpain.2018.11.009

Document Version:

Publisher's PDF, also known as Version of record

Document license:

Taverne

\section{Please check the document version of this publication:}

- A submitted manuscript is the version of the article upon submission and before peer-review. There can be important differences between the submitted version and the official published version of record.

People interested in the research are advised to contact the author for the final version of the publication, or visit the DOI to the publisher's website.

- The final author version and the galley proof are versions of the publication after peer review.

- The final published version features the final layout of the paper including the volume, issue and page numbers.

Link to publication

\footnotetext{
General rights rights.

- You may freely distribute the URL identifying the publication in the public portal. please follow below link for the End User Agreement:

www.umlib.nl/taverne-license

Take down policy

If you believe that this document breaches copyright please contact us at:

repository@maastrichtuniversity.nl

providing details and we will investigate your claim.
}

Copyright and moral rights for the publications made accessible in the public portal are retained by the authors and/or other copyright owners and it is a condition of accessing publications that users recognise and abide by the legal requirements associated with these

- Users may download and print one copy of any publication from the public portal for the purpose of private study or research.

- You may not further distribute the material or use it for any profit-making activity or commercial gain

If the publication is distributed under the terms of Article $25 \mathrm{fa}$ of the Dutch Copyright Act, indicated by the "Taverne" license above, 


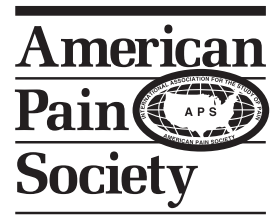

\title{
Original Reports
}

\section{The Pain Dynamics of Small Fiber Neuropathy}

\author{
Brigitte A. Brouwer, * Sander M.J. van Kuijk, ${ }^{\dagger}$ Anne Bouwhuis, ${ }^{\ddagger}$ Catharina G. Faber, ${ }^{\S}$ \\ Maarten van Kleef, * Ingemar S.J. Merkies, ${ }^{\S}$ ฯ and Janneke G.J. Hoeijmakers ${ }^{\S}$ \\ ${ }^{*}$ Department of Anesthesiology and Pain Medicine, ${ }^{\dagger}$ Department of Clinical Epidemiology and Medical Technology Assessment, \\ Maastricht University Medical Center+, 6202 AZ Maastricht, the Netherlands, ${ }^{\ddagger}$ Department of Anesthesiology, VU University \\ Medical Center, 1081 HV Amsterdam, the Netherlands, ${ }^{\S}$ Department of Neurology, Maastricht University Medical Center+, \\ 6202 AZ Maastricht, the Netherlands, "Department of Neurology, St. Elisabeth Hospital, Willemstad, Curaçao
}

\begin{abstract}
Pain is a central feature in small fiber neuropathy (SFN), with only moderate effects of pharmacologic treatment. The evaluation of the efficacy of therapies on pain has been driven by static measures, and a circadian cycle has been suggested. The aim of this study is to evaluate the pain dynamics in SFN. A total of 165 patients completed a standardized pain diary 4 times per week over a 4-week period. Patients used the 11-point numeric rating scale for average diurnal, nocturnal, and maximum pain, taking into account the circumstances in which pain emerged most. Medication used, SFN-related complaints, sleep quality, and anatomic location of pain were also assessed. Neuropathic pain showed a length-dependent pattern. For pain intensity, marginal higher pain scores at night than during the day were shown, likely not clinically meaningful, with stable lower pain intensities in weekends compared with weekdays. The average pain intensity was stable during the 4week period. Maximum pain was experienced mainly at rest and during sleep. Besides, pain intensity at night showed an inverse relationship with quality of sleep. In conclusion, for trials in SFN it is justified to use pain scores from any time of the day during short measurement periods.

Perspective: This article presents for the first time the pain dynamics of SFN. The effect of pharmacologic treatment in SFN is often disappointing, partly owing to insufficient trial designs. The results of this study have added value in the development of new proper clinical trials in SFN.
\end{abstract}

(c) 2018 by the American Pain Society

Key words: Small fiber neuropathy, painful neuropathy, pain diary, pain intensity, chronobiology.

S mall fiber neuropathy (SFN) is a condition in which the thinly myelinated $\mathrm{A} \delta$ - and unmyelinated C-fibers are affected. The clinical picture is dominated by neuropathic pain, but other sensory symptoms and autonomic complaints may also be present. ${ }^{19}$ SFN is not a rare disorder, but has mainly been underdiagnosed. There is a conservative minimum incidence estimation of 12 in
100,000 per year, and a minimum prevalence of 53 in $100,000 .{ }^{25}$ The diagnosis SFN is based on the clinical picture in combination with an abnormal intraepidermal nerve fiber density (IENFD) in skin biopsy, and/or abnormal temperature thresholds levels in quantitative sensory testing. ${ }^{6,19,33}$ In pure SFN, signs of large nerve fiber involvement are absent. ${ }^{19,33}$ Various disorders are associated with
Received May 13, 2018; Revised October 25, 2018; Accepted November $13,2018$.

C.G.F reports grants from European Union's Horizon 2020 research and innovation programme Marie Sklodowska-Curie grant for PAIN-Net, Molecule-to-man pain network (grant no. 721841), from European Union 7th Framework Programme (grant no. 602273) for the PROPANE study, from Prinses Beatrix Spierfonds (W.OR12-01, W.OR15-25), from Grifols and Lamepro for a trial on IVIg in small fiber neuropathy, and participates in steering committees/advisory boards for studies in small fiber neuropathy of Biogen/Convergence, Vertex and Chromocell, outside the submitted work. I.S. J.M. reports grants from Talecris Talents program, from GSB CIDP Foundation International, from Prinses Beatrix Spierfonds (W.OR12-01, W.OR1525), from European Union 7th Framework Programme (grant no. 602273). $A$ research foundation at the Maastricht University received honoraria on behalf of him for participation in steering committees of the Talecris ICE Study, LFB, CSL Behring, Novartis, Grifols, and Octapharma. He serves on the editorial board of the Journal of Peripheral Nervous system, is a member of the Inflammatory Neuropathy Consortium (INC), and member of the Peripheral Nerve Society, outside the submitted work. J.G.J.H. reports personal fees from Pfizer Inc. (travel funding and speakers' honorarium), grants from Prinses Beatrix Spierfonds (W.OK17-09), outside the submitted work. B.A.B., S.M.J.V.K., A.B., and M.V.K. have nothing to disclose.

This research did not receive any specific grant from funding agencies in the public, commercial, or not-for-profit sectors.

Supplementary data accompanying this article are available online at www.jpain.org and www.sciencedirect.com.

Address reprint requests to Janneke G.J. Hoeijmakers, MD, PhD, Department of Neurology, Maastricht University Medical Center+, PO Box 5800, 6202 AZ Maastricht, the Netherlands. E-mail:

j.hoeijmakers@mumc.nl

$1526-5900 / \$ 36.00$

(C) 2018 by the American Pain Society

https://doi.org/10.1016/j.jpain.2018.11.009 


\section{The Journal of Pain}

SFN, including metabolic, immune-mediated, infectious, toxic, and hereditary conditions. Although some of them are treatable, treatment usually does not resolve all symptoms. Besides, in about $60 \%$ of patients no associated condition can be found. ${ }^{7}$ In these cases, treatment is focused on pain relief, but often with disappointing results. ${ }^{19}$

Neuropathic pain has been defined as pain that arises as a direct consequence of a lesion or disease affecting the somatosensory system, including the small nerve fibers. ${ }^{12,21}$ Treatment of neuropathic pain is a challenge, because pain is multidimensional; pain does not just reflect an anatomic lesion or a deficit alongside the nervous system network, but is also seen as an unpleasant sensory and emotional experience. ${ }^{10}$ Recommendations for pharmacotherapy in neuropathic pain and SFN are available. ${ }^{4,11,17}$ Unfortunately, the efficacy is often only moderate, partly owing to the heterogeneous diagnostic criteria and poor phenotypic profiling in trials. ${ }^{11}$ Besides, there remains no consensus regarding which method is best to evaluate the efficacy of therapies on pain. Pain is assumed to be a static assessment parameter and generally approached as such in clinical trials. However, different pain conditions show distinctive pain patterns with fluctuations throughout the circadian cycle. ${ }^{15,27,28,30}$ Biopsychological, environmental, and genetic factors seem to play a role in the chronobiology of pain. ${ }^{15,30}$ For example, some inflammatory conditions intensify when cortisol levels are lowest after activity and at the end of the night. ${ }^{28,30}$ In contrast, patients with biliary colic suffer from the highest pain levels at the transition from day to night. ${ }^{15,27}$ Recently, circadian rhythms in neuropathic pain in diabetic neuropathy and postherpetic neuralgia have been demonstrated. ${ }^{15,16,24}$ Neuropathic pain showed an inverse diurnal pain intensity pattern, with the lowest pain score in the morning and a gradual increase of pain during the day. Treatment with gabapentin or morphine did not alter this pattern. ${ }^{24}$

No comprehensive research has been performed to evaluate pain dynamics in SFN. The aim of this observational study was to illustrate the dynamics of neuropathic pain in SFN in terms of average diurnal, nocturnal, and maximum pain, taking into account the circumstances in which pain is experienced most. If pain seems not to be a static concept, clinical trial designs have to be adapted.

\section{Methods}

\section{Patients}

A paper pain diary, accompanied by a detailed instruction brochure, was sent to 363 consecutive patients diagnosed with SFN at the Neuromuscular Center of the Maastricht University Medical Center+ between November 2009 and May 2014. For the diagnosis SFN, $\geq 2$ of the following sensory and autonomic symptoms, not otherwise explained, were required: neuropathic pain (burning, shooting, prickling, or itching), allodynia, hyperalgesia, thermal sensory loss, pinprick loss, restless legs syndrome, sicca syndrome, accommodation problems, hyperhidrosis or hypohydrosis micturition disturbances, impotence and/
Pain Dynamics of Small Fiber Neuropathy

or diminished ejaculation or lubrication, bowel disturbances (constipation, diarrhea, irritability, gastroparesis, cramps), hot flushes, orthostatic dizziness, and cardiac palpitations. ${ }^{19}$ In addition, a normal sural nerve conduction study and a decreased IENFD at the ankle and/or abnormal thermal thresholds in quantitative sensory testing were mandatory to establish the diagnosis SFN. ${ }^{6,19,33}$ Each patient completed the pain diary during a 4-week period. Only patients who were not part of any interventional clinical trial were included. For questions from the patients during the assessment period, they could contact the researcher by telephone.

The study was approved by the medical ethics committee of the Maastricht University Medical Center and the Board of directors in October 2009. Patients provided written informed consent before completing the questionnaires.

\section{Pain Diary}

To investigate the pain dynamics of SFN, a pain diary (see Supplementary data) was developed that was filled in on paper on Monday, Wednesday, Friday, and Sunday over a consecutive period of 4 weeks. After the 4-week assessment period, the patients returned the complete diary in a reply envelope. On each of the assessment days, the pain intensity was registered on an 11-point pain intensity numeric rating scale (PI-NRS) for average diurnal pain (awakening to 6 PM), average nocturnal pain (6 PM to awakening the next day), and maximum pain experienced during the past 24 hours. The PI-NRS, in which 0 is no pain and 10 is pain as bad as one can imagine, is commonly used in clinical trials and is suggested by the Initiative on Methods, Measurement, and Pain Assessment in Clinical Trials (IMMPACT) study group as one of the primary outcome measures. ${ }^{8}$ It can be applied to rate the actual pain or to describe the average, minimum, or worst pain during a past period.

To reveal the circumstances in which pain was most intense, the patients were asked to choose between the following options: a) at rest, b) during sleep, c) during exercise, d) during work/housekeeping, e) while standing, f) during warmth, g) during cold, and h) under other circumstance (open-ended question: describe which circumstance). For quantification of sleep quality, the patients had to indicate how well they slept the previous night on an 11-point NRS scale (from 0 [very bad] to 10 [excellent]).

Once a week, the average daily dose of pain medication used during the week was reported. The next options were given: a) no medication, b) acetaminophen, c) tramadol, d) opioids, e) gabapentin, f) pregabalin, g) amitriptyline, h) duloxetine, and i) other. Furthermore, also once a week, the 13-item SFN-symptoms inventory questionnaire (SFN-SIQ) was completed. $^{2,3}$ The SFN-SIQ contains the following SFNrelated symptoms, which are scored on a 4-point Likert scale (0 [never], 1 [sometimes], 2 [often], 4 [always]): 1) hyperhidrosis or hypohydrosis, 2) diarrhea, 3) constipation, 4) micturition problems, 5) dry eyes, 6) dry mouth, 7) orthostatic dizziness, 8) palpitations, 9) hot flashes, 
Brouwer et al

10) hypersensitive skin of the legs, 11) burning feet, 12) intolerance for sheets at the legs, and 13) restless legs at night. $^{2,3}$ Recently, the SFN-SIQ was transformed into an interval scale through Rasch analysis, facilitating its use in research. ${ }^{3}$

Finally, patients were asked to point out on a body map (front and back view) the location at which they experienced pain. In case they suffered from pain in multiple body parts with different pain intensities, they had to number the location with the most intense pain with a 1 , followed by the less painful body part with a 2, etcetera.

\section{Data Analysis and Statistics}

The percentage of missing values for all relevant questionnaire items was assessed to determine whether imputation strategies were needed. Baseline characteristics were obtained from patients' medical records (eg, gender, duration of symptoms, presence of voltage-gated sodium channel variants [including variants classified as variant with uncertain clinical significance, possibly pathogenic, probably pathogenic, and pathogenic ${ }^{34}$ ]) and reported as the mean value and standard deviation, or absolute number and percentage depending on the type of data. A linear mixed effects model was used with a random intercept to assess the stability of reported pain and maximum pain per day over a 4-week period and to examine possible differences in average nocturnal and diurnal pain, differences between weekdays and the weekend, and potential relation between sleep quality and nocturnal pain.

To assess the relation between mean reported pain and patient characteristics, each individual's pain score was averaged over the whole 4-week period. Multivariable linear regression analyses were used to assess the association of pain score with gender, age, having an underlying sodium channel mutation, the average Rasch-transformed SFN-SIQ score (raw sum scores were translated to interval-leveled logit scores and subsequently to centile metric scores (0 [no symptoms] to 100 [always all symptoms]), the duration of pain, and the use of prescribed analgesics.

A body map was used to visualize the relation between pain localization and intensity of pain. To make the data suitable for analysis, the data were rescored as followed: most intense pain numbered by patients with a 1 scored 10 points, the locations with number 2 scored 9 points, etcetera. Locations with numbers $\geq 10$ all scored 1 point and the body parts that were not numbered scored 0 points.

All analyses were performed in SPSS (IBM SPSS Statistics for Windows, Version 23.0. Armonk, NY). A $P \leq .05$ was considered to indicate statistical significance.

\section{Results}

Of all 363 patients who received a pain diary, a total of 165 patients $(46 \%)$ completed the diary. The maximum percentage of missing values was observed in the data of the fourth Sunday (6 participants [3.6\%] did not complete these questions). Because of the low percentage of missing values, and because all primary end
The Journal of Pain 3

points were computed using a linear mixed model that only omits missing instances from the analysis instead of whole subjects, it was chosen not to impute the dataset. Table 1 summarizes the basic demographic and clinical characteristics of the participants at baseline.

\section{Pain in SFN}

\section{Chronobiology of Pain}

A difference of $\geq 1$ point on the PI-NRS between daytime and night was not seen in most patients (only reported in $6.1 \%$ ). In $3.0 \%$ of patients, a difference of $\geq 2$ points was found. The mean day and night PI-NRS scores of all recorded days in the 4-week period are displayed in Fig 1. This figure shows consequent higher PINRS scores at night compared with daytime scores ( 0.37 points difference; $P<.001$ ).

When analyzing the influence of weekdays and weekend days, an even smaller difference in PI-NRS scores was found. On Sundays, patients reported a day and night average PI-NRS score that was 0.17 points lower as compared with the PI-NRS score on weekdays $(P<.001)$.

The average PI-NRS score over the whole period was 5.51. Using a mixed effects model, no linear change in intensity of pain over the 4-week period was observed (ie, disregarding differences between day and night, and between weekdays and weekends). The analysis yielded a coefficient of 0.002 on the PI-NRS score per

\section{Table 1. Baseline Characteristics of the Patients Participating in the Study}

\begin{tabular}{lc}
\hline & TотAL COHORT $(N=165)$ \\
\hline Age, years & $57.5 \pm 12.1$ \\
Gender & \\
Male & $74(44.8)$ \\
Female & $91(55.2)$ \\
Duration of pain, years & $9.4 \pm 6.8$ \\
Temperature threshold test & \\
Abnormal & $158(95.8)$ \\
Normal & $7(4.2)$ \\
IENFD & \\
Abnormal & $46(27.9)$ \\
Normal & $119(72.1)$ \\
Mutation & \\
SCN9A & $14(8.5)$ \\
SCN10A & $5(3.0)$ \\
SCN11A & $3(1.8)$ \\
Associated conditions* & \\
Autoimmune diseases & $32(19.4)$ \\
Glucose intolerance & $15(9.1)$ \\
Alcohol abuse & $6(3.6)$ \\
Chemotherapy & $6(3.6)$ \\
Vitamin B ${ }_{12}$ deficiency & $3(3.6)$ \\
Idiopathic & $103(62.4)$ \\
SFN-SIQ & \\
Opioid use (yes) & $43.4 \pm 8.7$ \\
\hline
\end{tabular}

SCN = sodium voltage-gated channel alpha subunit.

Data are expressed as mean \pm standard deviation or absolute number (\%).

*The diagnostics that were performed to search for associated conditions have been described previously.

†Raw sum scores were translated to centile metric scores $(0=$ no symptoms, $100=$ all symptoms always present $).^{3}$ 
$6.5-$

$6.0-$

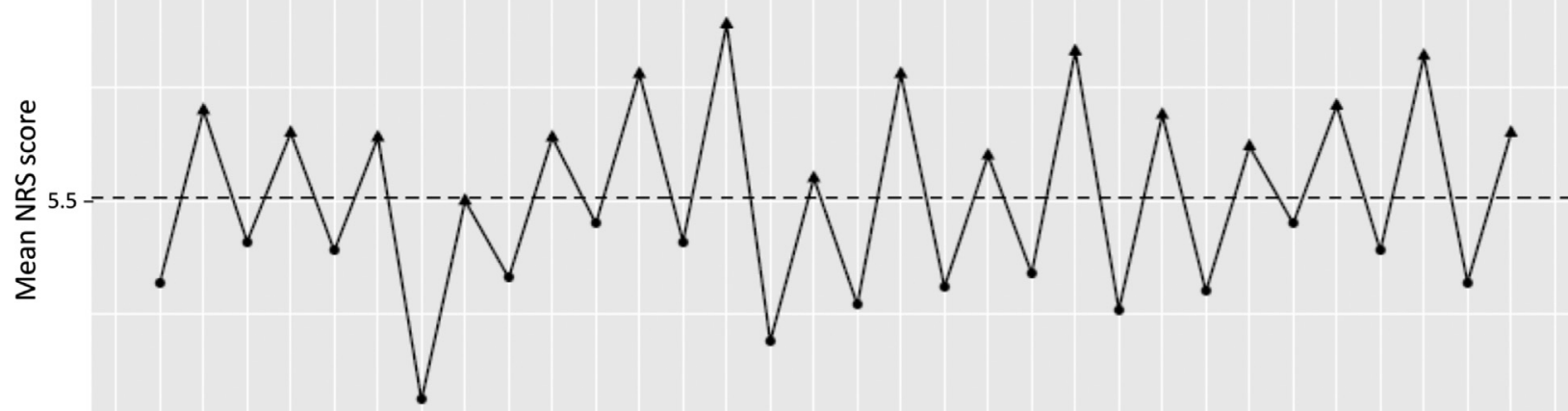

$5.0-$

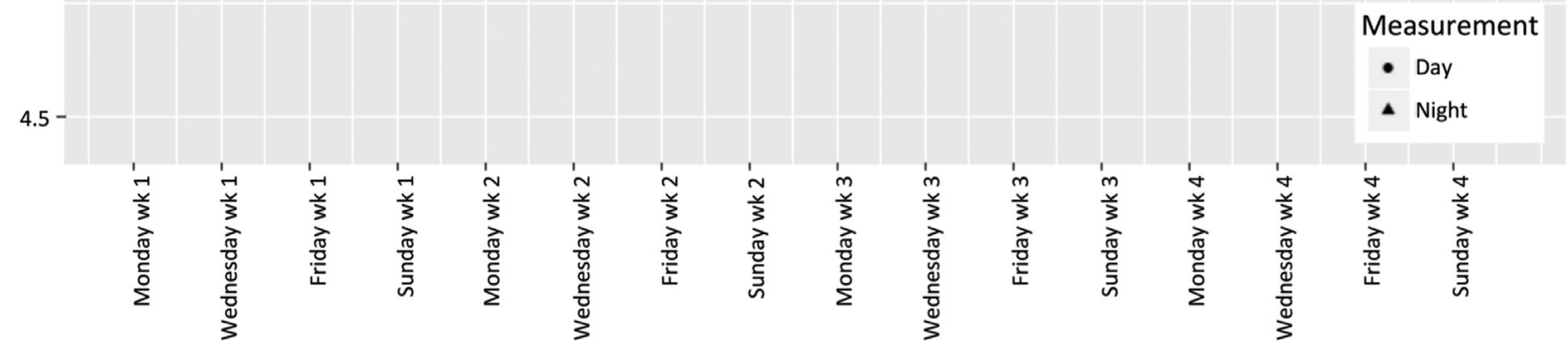

Figure 1. Mean PI-NRS scores of all patients $(n=165)$. At night, consequent higher PI-NRS scores are found compared with daytime scores $(0.37$ points difference; $P<.001)$, but this difference is likely not clinically meaningful.

measured day $(P=.534)$. The average maximum experienced pain per day was 6.14 , which was stable over the whole 4-week period as well $(B=-0.012, P=.903)$. Only 1 in 7 patients reported a maximum pain score of $\geq 8$.

\section{Circumstances and Maximum Pain}

Fig 2 shows the circumstances under which maximum pain was experienced. At rest $(48 \%)$ and during sleep (47\%), maximum pain was experienced most frequently, followed by pain while standing $(45 \%)$. There was no significant difference between warm (21\%) and cold weather (16\%). Long periods of sitting, for example, during a long car journey, were also frequently mentioned to be very painful. The results for weekdays and Sundays did not differ.

\section{Sleep Quality and Pain}

An association between reported nocturnal pain and sleep quality was observed. For each point increase in pain, an average decline in sleep quality of 0.300 was observed, both measured on an 11-point NRS (Spearman's rho, $-0.220, P=.004$ ).

\section{SFN-Related Symptoms and Pain}

For each point increase on the Rasch-transformed SFN-SIQ centile metric, an average increase of 0.11 was observed on the PI-NRS score $(P \leq .001)$.

\section{Patient Characteristics and Pain}

No associations between patient characteristics (age, gender, SCN-mutation, SFN-SIQ score, duration of pain, opioid use) and a difference of $\geq 1$ point at the PI-NRS score between daytime and night were present. The group of patients with $\geq 2$ points difference on the PINRS is too small for association studies.

Table 2 shows the results of the univariable and multivariable regression analysis, which included different patient characteristics. Patients with a voltage-gated sodium channel variant scored on average 0.91 points higher on the PI-NRS score $(P=.045)$ compared with patients without variant. After multivariable adjusted analysis, the difference decreased to $0.55(P=.166)$. Only nonsignificant differences between age groups, opioid use, and gender were found.

\section{Use of Analgesics}

Over the 4-week period, patients reported using the following pain medications: acetaminophen $(n=62$ 


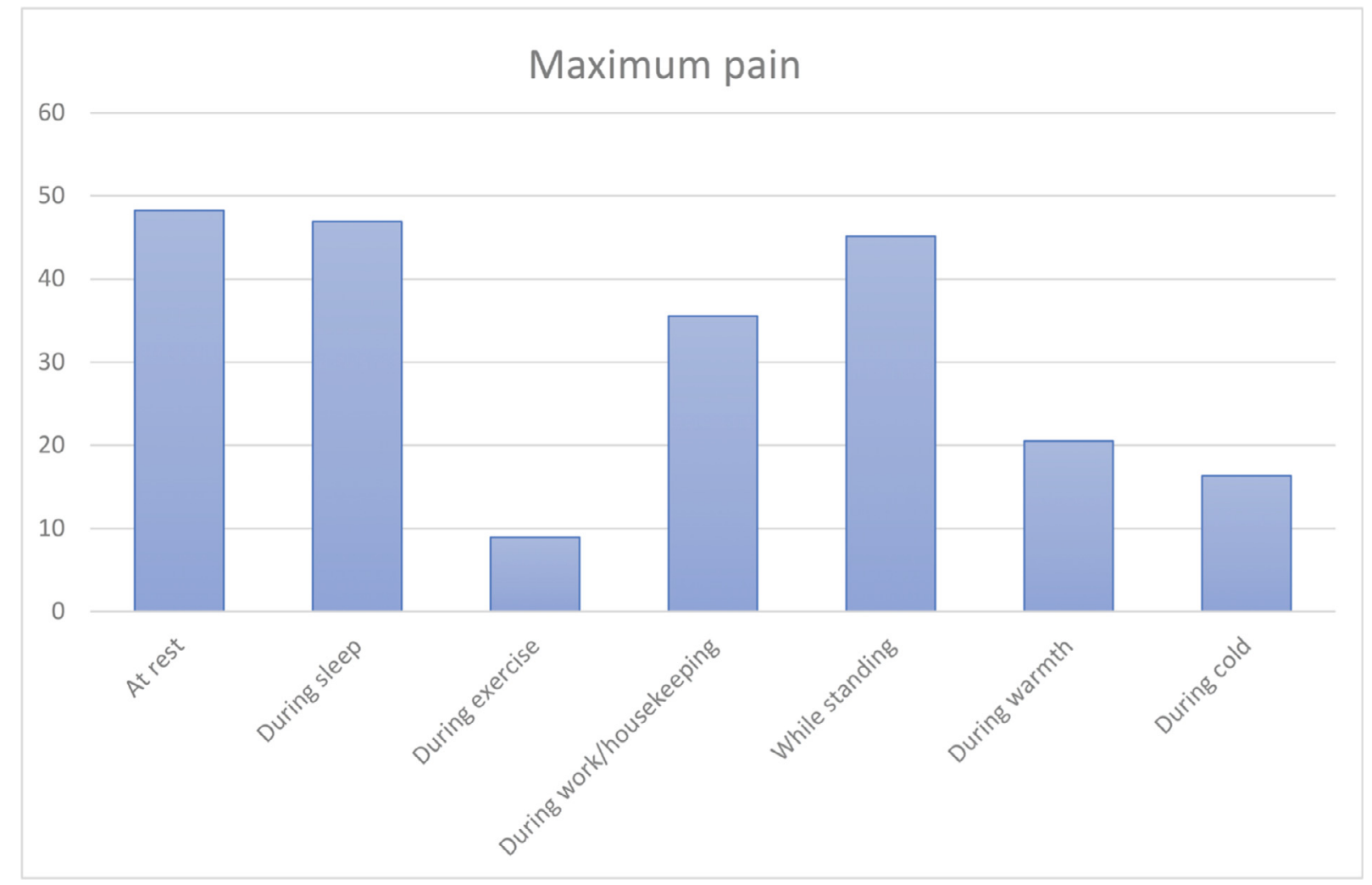

Figure 2. Circumstances under which maximum pain is experienced. Patients were asked if maximum pain was experienced under the indicated circumstances. The bars represent the percentages of positive answers.

[38\%]), calcium channel $\alpha 2 \delta$ subunit ligands (gabapentin and pregabalin, $\mathrm{n}=52[32 \%])$, tricyclic antidepressants (amitriptyline, $\mathrm{n}=30[18 \%])$, nonsteroidal anti-inflammatory drugs $(n=22[13 \%])$, carbamazepine $(n=2[1 \%])$, oxcarbamazepine ( $n=1[1 \%])$, serotonin-norepinephrine reuptake inhibitors ( duloxetine and venlafaxine, $n=24$ [15\%]), weak opioids $(n=20[12 \%])$, and strong opioids $(n=19[12 \%])$.

Table 2. Patient Characteristics as Determinants of 4-Week Average NRS Score

\begin{tabular}{|c|c|c|c|c|}
\hline & \multicolumn{2}{|c|}{ UNIVARIABLE ANALYSIS } & \multicolumn{2}{|c|}{ Multivariable Adjusted Analysis } \\
\hline & $\begin{array}{c}\text { REGRESSION COEFFIIIENT } \\
(95 \% \mathrm{Cl})\end{array}$ & P Value & $\begin{array}{c}\text { REGRESSION COEFFIIIENT } \\
(95 \% \mathrm{CI})\end{array}$ & P Value \\
\hline Age, years* (continuous) & $-0.19(-0.45$ to 0.01$)$ & .130 & $-0.02(-0.05$ to 0.00$)$ & .102 \\
\hline $18-64$ & $0.60(-0.06$ to 1.25$)$ & .075 & $0.65(-0.02$ to 1.33$)$ & .057 \\
\hline$\geq 65$ (ref.) & NA & NA & NA & NA \\
\hline \multicolumn{5}{|l|}{ Gender } \\
\hline Male & $-0.32(-0.93$ to 0.30$)$ & .311 & $-0.20(-0.80$ to 0.40$)$ & .507 \\
\hline Female (ref.) & NA & NA & NA & NA \\
\hline \multicolumn{5}{|c|}{ Confirmed mutation SCN9A-, SCN1OA- or SCN11A-gene } \\
\hline Yes & $0.91(0.23$ to 1.80$)$ & .045 & $0.55(-0.29$ to 1.39$)$ & 166 \\
\hline No (ref.) & NA & NA & NA & NA \\
\hline Total SFN-SIQ score ${ }^{\dagger}$ & $0.11(0.08$ to 0.15$)$ & $<.001$ & $0.10(0.07$ to 0.14$)$ & $<.001$ \\
\hline Duration of pain, years & $-0.02(-0.07$ to 0.02$)$ & .333 & $-0.02(-0.06$ to 0.02$)$ & .261 \\
\hline \multicolumn{5}{|l|}{ Opioid use } \\
\hline Yes & $0.51(-0.45$ to 1.46$)$ & .297 & $0.22(-0.76$ to 1.20$)$ & .658 \\
\hline No & NA & NA & NA & NA \\
\hline
\end{tabular}

$\mathrm{Cl}=$ confidence interval; $\mathrm{NA}=$ not applicable; ref. = reference category.

Regression coefficients are adjusted using multivariable regression.

*Age as a continuous variable and age dichotomized were analyzed separately. All multivariable adjusted regression coefficients were based on the model including age as a continuous variable.

†Raw sum scores were translated to centile metric scores (from 0 [no symptoms] to 100 [all symptoms always present]). 
6 The Journal of Pain

\section{Localization of Pain}

Fig 3 shows the pain distribution of neuropathic pain in patients with SFN. Severe pain was reported most frequently in the distal parts of the lower limbs. Most patients with SFN did not report pain in the head, torso, abdomen, groin, and buttocks.

\section{Discussion}

This study presents an overview of the characteristics of pain in patients diagnosed with SFN over time. Although pain intensity seems to show a circadian rhythm, with higher pain scores at night than during the day, and stable lower pain scores in weekends compared with weekdays, the differences in pain scores are small ( 0.37 and 0.17 , respectively), suggesting that clinical relevance is doubtful. This is supported by the finding that in $94 \%$ of patients the difference between day and night pain scores is $<1$ point. These results justify considering pain in SFN as a static concept, as is currently used for the design of clinical trials. The stable average pain intensity over a 4-week period permits short measurement periods for reliable results.

In accordance with the higher nocturnal pain scores, maximum pain was most frequently experienced at rest and during sleep. An explanation for pain at rest could be a lack of distraction; however, it is not clear whether spontaneous pain (or pain at rest) may be associated with other underlying mechanisms than evoked pain by touch or movement. ${ }^{13,18,31}$ Few patients reported maximum pain during exercise. Because patients were not asked which activities they had carried out that day, it is not clear if maximum pain indeed was not experienced during exercise, or that they did not perform any exercise at all.

An inverse relationship between pain intensity at night and quality of sleep was demonstrated. Sleep disturbances are common in chronic pain and seem to be reciprocal. ${ }^{29}$ Animal studies showed that melatonin levels in neuropathic pain are lower, which leads to activation of the microglia. ${ }^{20}$ Also, a decrease of extracellularreleased GABA in the cingulate cortex is suggested to be associated with sleep disturbances and neuropathic pain. ${ }^{23}$ Furthermore, neuropathic pain is commonly associated with depression and anxiety. These conditions are also known to interfere with sleep quality and may alter pain sensation. ${ }^{1}$ Because we have not included outcome measures in this field, we cannot provide information about the interrelationship between neuropathic pain, depression, and anxiety.

In the last couple of years, the role of voltage-gated sodium channel mutations in the pathophysiology of SFN has become clearer. ${ }^{5}$ Interestingly, greater pain intensity in patients with a voltage-gated sodium channel mutation compared with those without a mutation was found, but these results were not significant after correction using multivariable analysis. This outcome may be attributable to relatively low statistical power owing to a small sample size. In future studies, the influence of underlying conditions in SFN on pain should be further investigated.
Pain Dynamics of Small Fiber Neuropathy

The pain intensity scores visualized on the body map showed a clear distal-proximal gradient, reflecting a length-dependent pattern, with the most prominent symptoms distal in the limbs. This finding is in contrast with a recent study that demonstrated that the IENFD loss in patients diagnosed with SFN was similar in proximal and distal sites, suggesting a non-lengthdependent neuropathy. ${ }^{22}$ Pain distribution can be of interest by choosing the most appropriate therapy. For example, in patients with pain in the lower limbs, spinal cord stimulation might be an option. ${ }^{26}$ In patients with more generalized pain, systemic therapy will be preferred.

Research focused on the chronobiology and clinical characteristics of neuropathic pain will be of value for optimizing clinical trial design, but in literature it is also suggested that it will contribute to a better understanding of its pathophysiology by elucidating the associations between temporal patterns and endogenous factors (such as hormones and neurotransmitters), and between circadian rhythms and external factors (like exercise or temporal summation of stimuli). ${ }^{16}$ The current study did not investigate whether these factors are of importance in pain in SFN.

This study has also some limitations. Unfortunately, the current definition of SFN that is used is debatable. Although the IENFD is frequently considered the gold standard in the diagnostics of SFN, a true gold standard is lacking. The sensitivity of skin biopsy is moderate, because only in $\sim 30 \%$ of patients with the clinical picture of SFN is a decreased IENFD found. ${ }^{7}$ However, quantitative sensory testing lacks specificity; the test cannot discriminate between central and peripheral nervous system diseases. Moreover, the patient has to be alert and cooperative, and the results can be influenced malingering or other nonorganic factors. ${ }^{6,19}$

Regarding the pain characteristics that were found in this study, previous research about neuropathic pain in diabetes and postherpetic neuralgia showed an evident circadian rhythm. ${ }^{15,24}$ An explanation for the small differences between day and night scores in the current study might be to the use of average pain scores instead of actual pain scores at different time points.

In clinical trials, a change of $30 \%$ in pain intensity or a decrease of 2 points at the PI-NRS is often considered to be clinically relevant. ${ }^{8,9}$ This is a reason to debate the clinical relevance of a pain intensity difference between day and night of $<2$ points. However, because pain intensity variation during the day is not just interchangeable with pain reduction by medication, in future pain diary studies it could be of value to add an outcome measure like the Patient's Global Impression of Change scale. ${ }^{8,9}$

The response rate of completing the pain diaries was $47 \%$, implying that selection bias cannot be excluded. Moreover, because of the relatively small patient group, no associations between patient characteristics and a difference of $\geq 2$ points on the PI-NRS score between daytime and night could be demonstrated. Characterization of this patient group might also have implications for a clinical trial design. 
A

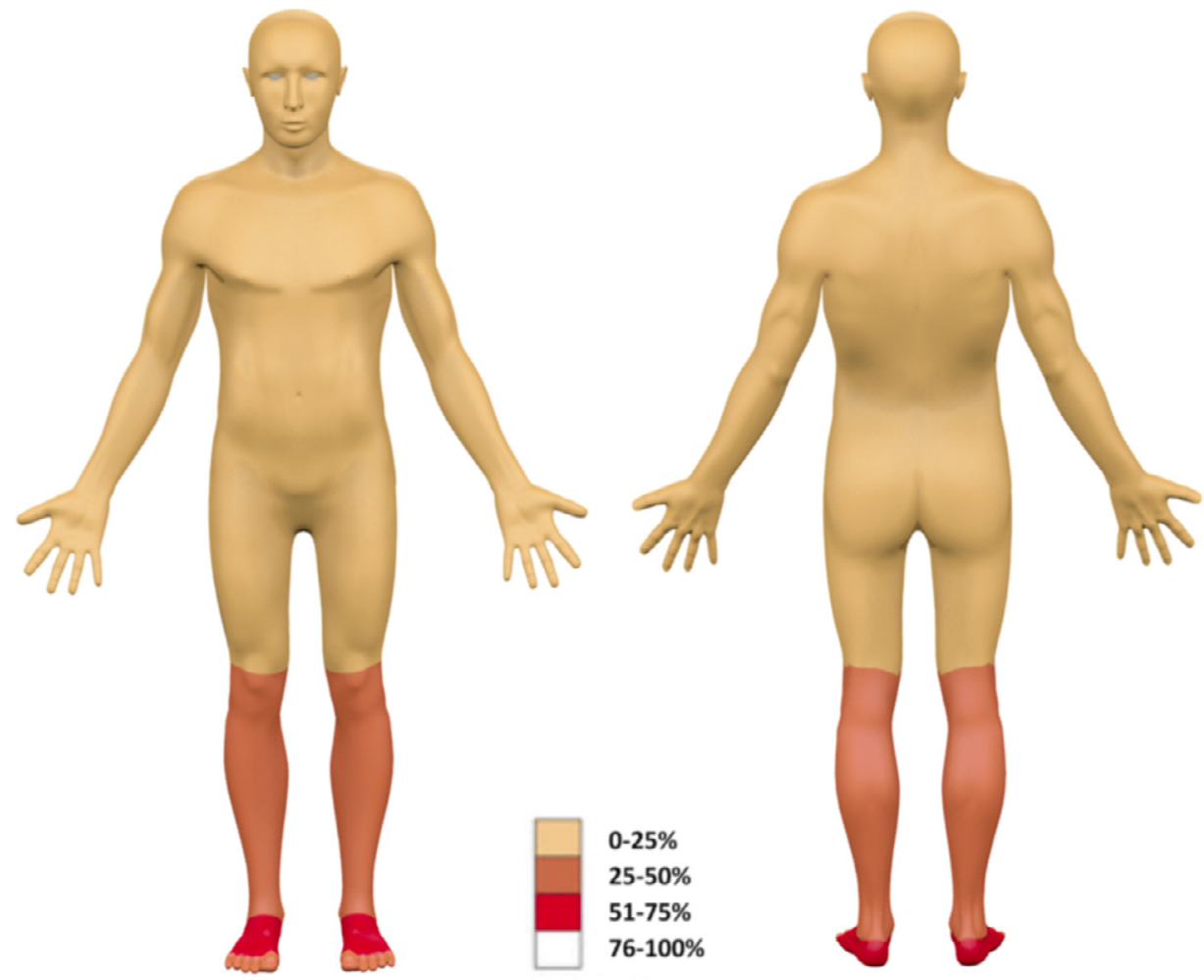

B

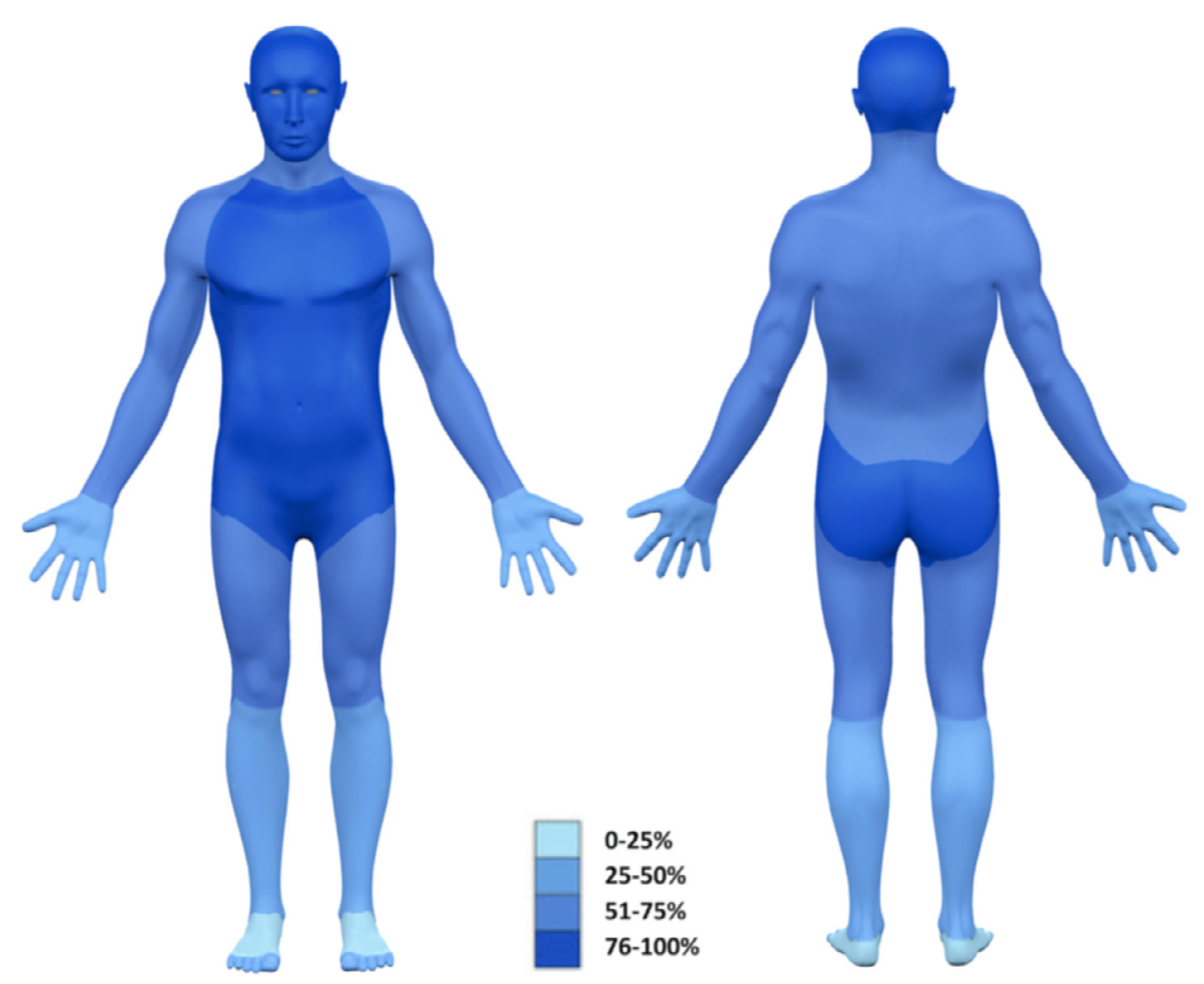

Figure 3. Distribution of neuropathic pain in SFN. (A) Frequencies of reported maximum pain. Severe pain was reported most frequent (red) in the distal parts of the lower limbs. (B) Frequencies of reported absent pain. Most patients with SFN did not report pain (dark blue) in the head, torso, abdomen, groin, and buttocks. 


\section{The Journal of Pain}

By using paper diaries instead of electronic questionnaires, the risk of noncompliance may have been greater. Besides, electronic diaries could have prevented missing values by giving warnings when questions were passed or by blocking the opportunity to continue with the next questions. Although recall bias was attempted to prevent by using a diary that had to be filled in 3 times a day, there was also a risk of back-filling. ${ }^{14,32}$ In today's society with multiple electronic devices within reach, including smartphones and tablets, the disadvantages of paper diaries in future studies may be prevented by using ecological momentary assessment. ${ }^{14}$ However, even though this method was not used in the current study, the data output was more than suitable to extract firm results.

In conclusion, for trials in SFN, it is justified to use pain intensity as a static measurement, because the average pain scores are stable during a 4-week period. Although pain intensity shows higher pain scores at night, the differences in pain scores are too small to be considered clinically relevant. Higher average pain scores are

\section{References}

1. Argoff CE: The coexistence of neuropathic pain, sleep, and psychiatric disorders: A novel treatment approach. Clin J Pain 23:15-22, 2007

2. Bakkers M, Merkies IS, Lauria G, Devigili G, Penza P, Lombardi R, Hermans MC, van Nes SI, De Baets M, Faber CG: Intraepidermal nerve fiber density and its application in sarcoidosis. Neurology 73:1142-1148, 2009

3. Brouwer BA, Bakkers M, Hoeijmakers JG, Faber CG, Merkies IS: Improving assessment in small fiber neuropathy. J Periph Nerv Syst 20:333-340, 2015

4. Brouwer BA, de Greef BT, Hoeijmakers JG, Geerts M, van Kleef M, Merkies IS, Faber CG: Neuropathic pain due to small fiber neuropathy in aging: Current management and future prospects. Drugs Aging 32:611-621, 2015

5. Brouwer BA, Merkies IS, Gerrits MM, Waxman SG, Hoeijmakers JG, Faber CG: Painful neuropathies: The emerging role of sodium channelopathies. J Periph Nerv Syst 19:5365,2014

6. Cazzato D, Lauria G: Small fibre neuropathy. Curr Opin Neurol 30:490-499, 2017

7. de Greef BTA, Hoeijmakers JGJ, Gorissen-Brouwers CML, Geerts M, Faber CG, Merkies ISJ: Associated conditions in small fiber neuropathy - a large cohort study and review of the literature. Eur J Neurol 25:348-355, 2018

8. Dworkin RH, Turk DC, Farrar JT, Haythornthwaite JA, Jensen MP, Katz NP, Kerns RD, Stucki G, Allen RR, Bellamy N, Carr DB, Chandler J, Cowan P, Dionne R, Galer BS, Hertz $S$, Jadad AR, Kramer LD, Manning DC, Martin S, McCormick CG, McDermott MP, McGrath P, Quessy S, Rappaport BA, Robbins W, Robinson JP, Rothman M, Royal MA, Simon L, Stauffer JW, Stein W, Tollett J, Wernicke J, Witter J, Immpact: Core outcome measures for chronic pain clinical trials: IMMPACT recommendations. Pain 113:9-19, 2005

9. Farrar JT, Young JP Jr, LaMoreaux L, Werth JL, Poole RM: Clinical importance of changes in chronic pain intensity
Pain Dynamics of Small Fiber Neuropathy

associated with the presence of more SFN-related symptoms, and clinically, neuropathic pain in SFN shows a length-dependent pattern.

\section{Supplementary Data}

The pain diary that was used to evaluate the pain dynamics of SFN. The original pain diary was presented in Dutch. To clarify the content, a translation in English is given.

\section{Acknowledgments}

We thank Kim Bekelaar and Aurélie Degeneffe for the assistance in collecting the data.

\section{Supplementary data}

Supplementary data related to this article can be found at https://doi.org/10.1016/j.jpain.2018.11.009.

measured on an 11-point numerical pain rating scale. Pain 94:149-158, 2001

10. Finnerup NB, Attal N: Pharmacotherapy of neuropathic pain: Time to rewrite the rulebook? Pain Manag 6:1-3, 2016

11. Finnerup NB, Attal N, Haroutounian S, McNicol E, Baron R, Dworkin RH, Gilron I, Haanpaa M, Hansson P, Jensen TS, Kamerman PR, Lund K, Moore A, Raja SN, Rice AS, Rowbotham $M$, Sena E, Siddall $P$, Smith $B H$, Wallace M: Pharmacotherapy for neuropathic pain in adults: A systematic review and meta-analysis. Lancet Neurol 14:162-173, 2015

12. Finnerup NB, Haroutounian $S$, Kamerman $P$, Baron $R$, Bennett DL, Bouhassira D, Cruccu G, Freeman R, Hansson $P$ Nurmikko T, Raja SN, Rice AS, Serra J, Smith BH, Treede RD, Jensen TS: Neuropathic pain: An updated grading system for research and clinical practice. Pain 157:1599-1606, 2016

13. Garcia-Larrea L, Convers $\mathrm{P}$, Magnin M, Andre-Obadia N, Peyron R, Laurent B, Mauguiere F: Laser-evoked potential abnormalities in central pain patients: The influence of spontaneous and provoked pain. Brain 125:2766-2781, 2002

14. Gendreau M, Hufford MR, Stone AA: Measuring clinical pain in chronic widespread pain: Selected methodological issues. Best Pract Res Clin Rheumatol 17:575-592, 2003

15. Gilron I, Bailey JM, Vandenkerkhof EG: Chronobiological characteristics of neuropathic pain: Clinical predictors of diurnal pain rhythmicity. Clin J Pain 29:755-759, 2013

16. Gilron I, Ghasemlou N: Chronobiology of chronic pain: Focus on diurnal rhythmicity of neuropathic pain. Curr Opin Support Palliat Care 8:429-436, 2014

17. Gilron I, Watson CPN, Cahill CM, Moulin DE: Neuropathic pain: A practical guide for the clinician. CMAJ $175: 265-275,2006$

18. Gottrup H, Bach FW, Juhl G, Jensen TS: Differential effect of ketamine and lidocaine on spontaneous and mechanical evoked pain in patients with nerve injury pain. Anesthesiology 104:527-536, 2006 


\section{Brouwer et al}

19. Hoeijmakers JG, Faber CG, Lauria G, Merkies IS, Waxman SG: Small-fibre neuropathies-advances in diagnosis, pathophysiology and management. Nat Rev Neurol 8:369379,2012

20. Huang $C T$, Chiang RP, Chen CL, Tsai YJ: Sleep deprivation aggravates median nerve injury-induced neuropathic pain and enhances microglial activation by suppressing melatonin secretion. Sleep 37:1513-1523, 2014

21. Jensen TS, Baron R, Haanpaa M, Kalso E, Loeser JD, Rice AS, Treede RD: A new definition of neuropathic pain. Pain 152:2204-2205, 2011

22. Khoshnoodi MA, Truelove S, Burakgazi A, Hoke A, Mammen AL, Polydefkis M: Longitudinal assessment of small fiber neuropathy: Evidence of a non-length-dependent distal axonopathy. JAMA Neurol 73:684-690, 2016

23. Narita M, Niikura K, Nanjo-Niikura K, Narita M, Furuya M, Yamashita A, Saeki M, Matsushima Y, Imai S, Shimizu T, Asato M, Kuzumaki N, Okutsu D, Miyoshi K, Suzuki M, Tsukiyama Y, Konno M, Yomiya K, Matoba M, Suzuki T: Sleep disturbances in a neuropathic pain-like condition in the mouse are associated with altered GABAergic transmission in the cingulate cortex. Pain 152:1358-1372, 2011

24. Odrcich M, Bailey JM, Cahill CM, Gilron I: Chronobiological characteristics of painful diabetic neuropathy and postherpetic neuralgia: Diurnal pain variation and effects of analgesic therapy. Pain 120:207-212, 2006

25. Peters MJ, Bakkers M, Merkies IS, Hoeijmakers JG, van Raak EP, Faber CG: Incidence and prevalence of small-fiber neuropathy: A survey in the Netherlands. Neurology 81:1356-1360, 2013

26. Pluijms WA, Slangen R, Bakkers M, Faber CG, Merkies IS, Kessels AG, Dirksen CD, Joosten EA, Reulen JP, van Dongen RT, Schaper NC, van Kleef M: Pain relief and quality-oflife improvement after spinal cord stimulation in painful
The Journal of Pain 9

diabetic polyneuropathy: A pilot study. $\mathrm{Br} J$ Anaesth 109:623-629, 2012

27. Rigas B, Torosis J, McDougall CJ, Vener KJ, Spiro HM: The circadian rhythm of biliary colic. J Clin Gastroenterol 12:409-414, 1990

28. Sierakowski S, Cutolo M: Morning symptoms in rheumatoid arthritis: A defining characteristic and marker of active disease. Scand J Rheumatol Suppl 125:1-5, 2011

29. Smith MT, Haythornthwaite JA: How do sleep disturbance and chronic pain inter-relate? Insights from the longitudinal and cognitive-behavioral clinical trials literature. Sleep Med Rev 8:119-132, 2004

30. Smolensky MH, Portaluppi F, Manfredini R, Hermida RC, Tiseo R, Sackett-Lundeen LL, Haus EL: Diurnal and twenty-four hour patterning of human diseases: Acute and chronic common and uncommon medical conditions. Sleep Med Rev 21:12-22, 2015

31. Srikandarajah S, Gilron I: Systematic review of movement-evoked pain versus pain at rest in postsurgical clinical trials and meta-analyses: A fundamental distinction requiring standardized measurement. Pain 152:1734-1739, 2011

32. Stone AA, Broderick JE: Real-time data collection for pain: Appraisal and current status. Pain Med 8(Suppl 3): S85-S93, 2007

33. Tesfaye S, Boulton AJ, Dyck PJ, Freeman R, Horowitz M, Kempler P, Lauria G, Malik RA, Spallone V, Vinik A, Bernardi L, Valensi P: Diabetic neuropathies: Update on definitions, diagnostic criteria, estimation of severity, and treatments. Diabetes Care 33:2285-2293, 2010

34. Waxman SG, Merkies IS, Gerrits MM, Dib-Hajj SD, Lauria G, Cox JJ, Wood JN, Woods CG, Drenth JP, Faber CG: Sodium channel genes in pain-related disorders: Phenotype-genotype associations and recommendations for clinical use. Lancet Neurol 13:1152-1160, 2014 